\title{
The long and the short of it: Some statistics from the 2012 Lappet-faced Vulture chick ringing in the Namib
}

\section{Holger Kolberg ${ }^{1}$ and Peter Bridgeford ${ }^{2}$}

Vultures Namibia, P.O. Box 3699, Walvis Bay, Namibia

1 email: holgerk@mweb.com.na, 2email: pmbridge@iway.na

Vultures Namibia once again ringed Lappet-faced Vulture Torgos tracheliotos chicks in the NamibNaukluft Park during October 2012 as part of an on-going long-term study of the breeding of these vultures in the central Namib. A total of 76 nests were visited from Sesriem in the south to near the Swakop River in the north (Figure 1). The chicks ringed hatched between 12 June 2012 and 26 August 2012. We use the standard wing length and the table in Mundy (1982) to determine the age of the chick and hence the hatching date.

The trees used for nesting were predominantly Acacia erioloba with a total of five different tree species used in 2012 (Table 1). The height of the nest above the ground is measured to the nearest centimetre using a tape measure and the average, minimum and maximum height are given in Table 1. This is also the height of the tree because the nests are always in the top-most branches of the tree. The average tree height compares favourably with the height given by Mundy (1982) for Gonarezhou (7.1m) where birds preferred Terminalia trees but is quite a bit lower than the average $8.8 \mathrm{~m}$ height recorded by the same author for north-western Zimbabwe.

Table 1: Tree species, number of trees and average, minimum and maximum height of trees used by nesting Lappet-faced Vultures in the Namib in 2012

\begin{tabular}{|c|c|c|c|c|}
\hline Tree species & No & Average height (m) & Min & Max \\
\hline Acacia erioloba & 62 & 6.59 & 3.58 & 11.30 \\
\hline Acacia tortilis & 7 & 6.82 & 4.00 & 10.20 \\
\hline Acacia reficiens & 4 & 4.08 & 2.80 & 5.80 \\
\hline Ziziphus mucronata & 2 & 3.38 & 3.00 & 3.75 \\
\hline Euclea pseudebenus & 1 & 3.50 & 3.50 & 3.50 \\
\hline Total & 76 & 6.33 & & \\
\hline
\end{tabular}




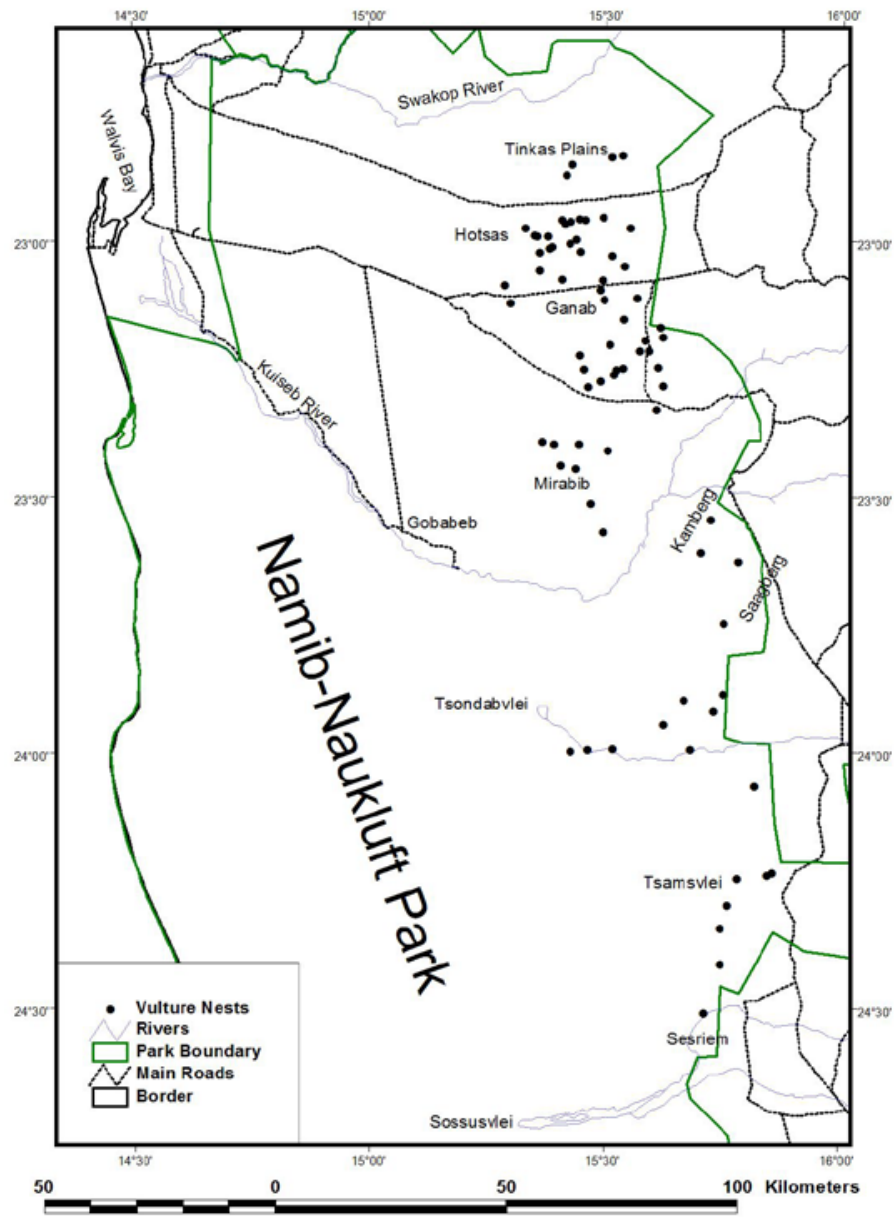

Figure 1: Lappet-faced Vulture nests in the Namib-Naukluft Park, Namibia

The trees are individually numbered tree seven times before (Table 2). It which allows us to record how often a is interesting that one nest was used tree is used. Three trees were used two years in a row i.e. in 2011 and once before, one tree twice and one 2012 (tree No. 327). 
Table 2: Tree number and years used by nesting Lappet-faced Vultures in the Namib

\begin{tabular}{|l|l|}
\hline Tree Number & Used in \\
\hline 63 & $1995,1997,1999,2003,2006,2008,2010,2012$ \\
\hline 219 & 1999,2012 \\
\hline 250 & 2000,2012 \\
\hline 327 & $2008,2011,2012$ \\
\hline 400 & 2010,2012 \\
\hline
\end{tabular}

The size of the nest, the cup and the depth of the cup are also recorded and a summary of that data is given in Table 3 ( $\mathrm{n}=71)$. Mundy (1982) gives data on nest and cup diameter and a comparison between his and our data is given in Table 4 .

Table 3: Values on nest and cup area* and cup depth of Lappet-faced Vulture nests measured in the Namib in 2012

\begin{tabular}{|c|c|c|c|}
\hline & Nest Area $\left.\mathbf{( m}^{\mathbf{2}}\right)$ & Cup Area $\left.\mathbf{( m}^{\mathbf{2}}\right)$ & Cup Depth (mm) \\
\hline average & 2.07 & 0.66 & 90.5 \\
\hline std dev & 0.72 & 0.23 & 39.4 \\
\hline min & 0.73 & 0.23 & 0.0 \\
\hline max & 4.34 & 1.32 & 190.0 \\
\hline
\end{tabular}

*Nest and cup area used rather than diameter as nests are usually elliptical in shape.

Table 4: Comparison of nest parameter data given by Mundy (1982) and this study

\begin{tabular}{|c|c|c|c|c|}
\hline & \multicolumn{2}{|c|}{ Mundy } & \multicolumn{2}{c|}{ This Study } \\
\hline $\mathbf{n}$ & Nest & Cup & Nest & Cup \\
\hline Average (mm) & 30 & & 71 & \\
\hline Std. Dev. (mm) & 1780 & 715 & 1799 & 1004 \\
\hline Min. (mm) & & 165 & 345 & 193 \\
\hline Max. (mm) & & & 1100 & 600 \\
\hline
\end{tabular}

The average minimum distance more than the figure given by Mundy between nests was $3.967 \mathrm{~km}$ (std. dev. (1982) for Gonarezhou $(2.9 \mathrm{~km} \pm 2.1$ ) $=2.839 \mathrm{~km}$ ) with a range of 0.524 to but quite a lot less than the figure for $15.873 \mathrm{~km}$. This is about a kilometre north-western Zimbabwe $(7 \mathrm{~km})$.

\section{References:}

Mundy, P.J. 1982. The comparative biology of southern African vultures. Vulture Study Group, Johannesburg. 